Бусыгин Алексей Геннадьевич

аспирант кафедры прикладной социологии Уральского федерального университета имени первого Президента России Б.Н. Ельцина

\section{МЕХАНИЗМЫ И УСЛОВИЯ ФОРМИРОВАНИЯ ПРАВОСЛАВНОЙ ИДЕНТИЧНОСТИ [1]}

\section{Аннотация:}

В статье в качестве механизмов формирования православной идентичности рассматриваются процессы интернализации и социализации личности, которые происходят в условиях глобализации российского общества. Как следствие социализации личности в институциональной среде описывается содержание православной идентичности. На основе эмпирических материалов, собранных в рамках качественного социологического исследования, анализируются периоды религиозной социализации индивида в институте религии и роли агентов религиозной социализации, участвующих в формировании православной идентичности. Автор отмечает, что православная идентичность создается посредством включения человека в систему конфессиональных отношений, восприятия и внутреннего усвоения им религиозных доктрин, ценностей и норм. По результатам работы сделан вывод, что православная идентичность имеет внутренние (когнитивный, ценностный, эмоциональный) и внешние (поведенческий, коммуникативный, статусно-ролевой) компоненты.

\section{Ключевые слова:}

первичная социализация, вторичная социализация, интернализация, идентичность, религиозная идентичность, православная идентичность, религиозная социализация, воцерковление.
Busygin Aleksey Gennadyevich

PhD student Applied Sociology Department, Ural Federal University

\section{MECHANISMS AND CONDITIONS FOR THE DEVELOPMENT OF ORTHODOX IDENTITY [1]}

The research considers the development of Orthodox identity through the concepts of internalization and socialization of the personality in the context of globalization of the Russian society. The study describes Orthodox identity as a result of the socialization of the personality in the institutional environment. Based on the empirical materials collected during the qualitative social research, the author analyzes the periods of religious socialization of the individual in the religious institution and the role of agents of religious socialization when developing the Orthodox identity. The paper notes that Orthodox identity is created by the inclusion of a person in the system of denominational relations, perception, and internal assimilation of religious doctrines, values, and standards. The author concludes that Orthodox identity has internal (cognitive, value, emotional) and external (behavioral, communicative, status and role) components.

Keywords:

primary socialization, secondary socialization, internalization, identity, religious identity, Orthodox identity, religious socialization, churching.

Новой отличительной чертой социальной жизни российского общества последних 25 лет стало снятие действовавших в течение предшествующих 70 лет законодательных ограничений на деятельность религиозных объединений. Произошли не только юридические изменения, фактически трансформировались роли религиозных объединений в жизни социума, изменился характер государственно-конфессиональных отношений. Наблюдалось внутреннее преобразование многих социальных институтов, выступавших в качестве агентов социализации, в частности института религии. Столь явные перемены не могли не отразиться на религиозной идентичности разных социальных групп, в том числе молодежи.

Вместе с тем, несмотря на богатую исследовательскую традицию, вопрос о формировании религиозной идентичности остается открытым. Многие российские ученые, включая религиозную идентичность в область научных интересов, в основном занимались проблемой ее концептуализации и типологизации, например, выделим работы по типологиям религиозной идентичности Т.C. Прониной и С.В. Рыжовой [2]. В данной статье мы постарались выйти за рамки описания религиозной идентичности как типологии и рассмотреть ее как динамичный процесс, формирование которого обусловлено временными периодами и механизмами социального конструирования личности. Делая предметом анализа взаимосвязь таких категорий, как «идентичность», «интернализация», «социализация» и «глобализация», мы в первую очередь опирались на работы П. Бергера, Т. Лукмана [3] и 3. Баумана [4].

Т. Лукман и П. Бергер, базируясь на положениях Дж.Г. Мида [5], предлагают теорию социализации в качестве основы для категории идентичности. Социализацию ученые рассматривают как непрерывный процесс и результат субъективного упорядочивания индивидом социального опыта или социального «знания» общества. Идентичность, по их мнению, является ключевым 
элементом субъективной реальности и формируется социальными процессами. Речь идет о том, что она имеет социальную природу, ее базисом служат социальные взаимодействия. Согласно П. Бергеру и Т. Лукману, главным пунктом социализации выступает интернализация - механизм восприятия и усвоения индивидом знания об окружающей реальности [6, с. 211-213].

П. Бергер и Т. Лукман различают первичную и вторичную социализацию. Первое знакомство с социальной реальностью происходит в процессе первичной социализации. Значимые другие, интерпретируя информацию, передают ее для нас как несомненную реальность, основными элементами которой становятся освоение языка, ключевых образцов поведения, а также аппарат легитимации передаваемой нам реальности. Исследователи утверждают, что первичная социализация представляет собой нечто большее, чем когнитивное обучение, поскольку сопряжена с большой эмоциональной нагрузкой, напрямую связанной с формированием идентичности у индивида [7].

Первичная социализация завершается в тот момент, когда человек сталкивается с альтернативным образцом мышления и поведения и выходит за пределы привычной социальной среды и принятой им социальной реальности (например, когда ребенок покидает семью). На обозначенном этапе возникают две проблемы: 1) отношения с другими людьми больше не выстраиваются на основе эмоциональной близости, 2) принятая индивидом при первичной социализации социальная реальность под давлением альтернатив распадается для него на несколько частей. Например, посещение школы не обязательно предполагает полную идентификацию и эмоциональную вовлеченность: «он может с радостью покинуть мир арифметики, как только выйдет из класса» [8, с. 231]. Это дает индивиду возможность обособления части «я» и соответствующей ей реальности от реальности в определенной ситуации, тогда он выстраивает дистанции между целостным «я» и реальностью с одной стороны и частичным ролевым «я» и той реальностью с другой стороны.

В связи с этим П. Бергер и Т. Лукман говорят о наслоении вторичной социализации на первичную: новая интернализованная информация накладывается на знания, приобретенные ранее. Так, согласно теоретикам, «вторичная социализация представляет собой интернализацию институциональных или институционально обоснованных "подмиров"» [9, с. 224]. Степень и характер этих институциональных наслоений определяются особенностями вовлеченности индивида в соответствующую трудовую деятельность. Кроме того, вероятен конфликт согласованности между первичной системой знания и вторичной (например, нежелание учиться в школе, идти в армию и т. д.). По мнению П. Бергера и Т. Лукмана, вторичная социализация менее устойчива, поскольку соответствующая ей реальность не так глубоко укоренена в сознании индивида и поддается смещению. Тем не менее существуют тотальные институты, которые вмешиваются в «я»-реальность от первичной социализации и различными специальными механизмами направляют ее в иное русло.

Какое же место занимает идентичность в этом длительном процессе? Согласно П. Бергеру и Т. Лукману, феномен идентичности не существует в отрыве от социальной реальности. Идентичность - это то, что мы демонстрируем перед встречающимися нам в жизни «другими», обобщенные ожидания и установки, которые в некотором смысле упрощают и замещают необходимость эмоциональной связи и близости с «другими». Поэтому на этапе вторичной социализации в процессе деловой деятельности, в рамках той или иной социальной структуры мы вынуждены заниматься поиском идентичности, которая бы соответствовала общим ожиданиям, и затем постоянно ее поддерживать. Поддержание такой идентичности предполагает, что в нас есть заинтересованность принимать участие в определенном социальном порядке. В то же время индивид в этом процессе зависит от эмоционального признания ее «другими» (особенно такими значимыми, как жена, дети, коллеги, все прочие люди, с которыми человек находится в повседневном контакте). П. Бергер и Т. Лукман обрамляют феномен идентичности следующим образом: «Подобно всякой субъективной реальности, она находится в диалектической взаимосвязи с обществом. Идентичность фрормируется социальными процессами. Однажды выкристаллизовавшись, она поддерживается, видоизменяется или даже переформируется социальными отношениями» [10, с. 279].

Таким образом, идентичность формируется в процессе первичной и вторичной социализации вначале под влиянием той социальной реальности, которую нам демонстрирует семья, далее в ее реформатирование включаются социальные институты и значимые другие, для развития и сохранения деловых отношений с которыми мы ищем и демонстрируем ее. По сути на локальном уровне идентичность - это «мост» между человеком и обществом, выстроенный из представлений и знаний о реальности. В глобальном плане это последствия социального конструирования реальности, феномен, призванный сохранять социальный порядок заданной институциональной реальности в обществе. В частности, религиозная идентичность также зависит от значимых других (агентов) и формируется в процессе религиозной социализации индивида в институте религии посредством включения человека в систему конфессиональных отношений, восприятия и внутреннего усвоения им религиозных доктрин, ценностей и норм. 
Однако в современном мире в результате процесса глобализации условия фоорирования и устойчивость идентичности подверглись характерным изменениям. Для раскрытия обозначенной проблемы мы обратились к работе «Индивидуализированное общество» британского социолога 3. Баумана. Его подход интересен нам прежде всего тесной связью с феноменом глобализации, которому сам ученый дает характеристику «текучая современность». Исследователь использует данную метафору для описания эпохи, в которой человечество переходит от сложного структурированного мира к гибкому и свободному от различных институциональных границ и условий миру. Человек становится мобильным и не связанным длительными обязательствами. Все, что он создает, он может и изменить. Такой переход, как утверждает автор, повлек за собой трансформации в человеческой жизни. Поэтому, указывая на принципиально новые аспекты глобализированной реальности, 3. Бауман выделяет другую ее отличительную черту и одновременно следствие - индивидуализацию. В его теоретической схеме индивидуализация является результатом влияния глобального мира, быстро размывающего фиксированные позиции индивида в обществе. Кроме эпитета рискованной неопределенности, это изменчивое состояние он характеризует с помощью термина «неустроенность», говоря о невозможности сегодня получить какое бы то ни было прочное «ложе» для сохранения стабильности. В подобных условиях вся жизнь человека превращается в задачу непрерывного поиска, выбора и смены идентичности. Мыслитель пишет, что «идентичности существуют сегодня исключительно в процессе постоянного пересмотра. Формация идентичности или ее ре-фоормация разворачивается в качестве пожизненной задачи, никогда не завершенной; нет момента жизни, когда идентичность "финальна"» [11].

По мнению 3. Баумана, вследствие глобализации общества одна из главных особенностей нашего времени кроется в конвергенции идентичности и потребления. Современное общество относится к своим членам прежде всего как к потребителям. Чтобы быть признанным членом социума, индивид вынужден регулярно вносить вклад в рынок потребления, если он не покупает, значит, не выполняет свои социальные обязательства [12, р. 191]. Тем самым потребление как материальная ценность становится новым механизмом вторичной социализации человека и ключевой причиной неустойчивости индивидуальной идентичности и размывания институциональных границ. Таким образом, фрормирование и устойчивость религиозной личности в условиях глобализации российского общества раскрываются в ценностном противоречии, которому мы уделили внимание позже.

Опираясь на теоретические конструкты П. Бергера, Т. Лукмана и 3. Баумана и следуя логике понимания того, как формируется идентичность, мы предполагаем, что каждый человек имеет множество идентичностей, которые образуют в его сознании суммарную идентичность. Мы считаем, что современная православная идентичность - это прежде всего комплексная идентичность, возникшая на стыке религиозной, культурной, национальной, гражданско-политической идентичностей, при этом каждая отдельно взятая идентичность состоит из элементов, которые обладают тесными взаимосвязью и взаимозависимостью. Например, религиозная и культурная идентичности содержат языковой компонент (русский - церковнославянский), связанный через языковую компетенцию, особенности тезауруса, стиль речи и многое другое. Религиозная идентичность - очень «чувствительный» феномен к любого рода явлениям, процессам, происходящим в социальном поле. Так, исследователь О.Н. Павлова, подчеркивая изменчивость характеристик идентичности, утверждает, что «в каждый конкретный момент каждый из нас представляет собой комбинацию серий идентификационных компонентов, и эти компоненты могут сочетаться, а их комбинации в свою очередь меняться различными способами» [13]. На основании эмпирического материала мы рассмотрели процесс формирования и составляющие религиозной идентичности, формирующие ядро православной идентичности.

Эмпирической базой для выводов в статье служат материалы, собранные в рамках качественного социологического исследования, проведенного автором в июне - августе 2018 г. Респондентами выступили представители православной молодежи в возрасте от 18 до 30 лет. Длительность интервью - 20-65 мин., в среднем по 35 мин. Беседы проводились в зданиях университета и православных храмов в спокойной обстановке, без участия третьих лиц. Методом полуструктурированных глубинных интервью опрошено 15 человек.

Процесс фрормирования религиозной идентичности всегда начинается с одной из двух возможных отправных точек: 1) рождение и детство в религиозной семье, когда религиозная социализация совпадает с первичной социализацией; 2) знакомство с религией за пределами института семьи, в школе, университете, на работе - вторичная социализация. Формирование религиозной идентичности вне института семьи мы условно разделили на подготовительный и активный периоды.

Когда человек рождается в религиозной семье, все знания о данной социальной реальности транслируются ему родными и воспринимаются им как единственная объективная реальность. В детстве интернализируемые знания о религии ребенок получает в некой сказочной повествовательной форме: «в детстве я очень любил смотреть Библию с картинками» (Андрей, 
25 лет). Постепенно, с развитием личности и увеличением объема интернируемого знания о социальном мире, элементы религиозного знания начинают трактоваться как объективно более реальные: «Родители православные оба, и поэтому с детства уже определен путь» (Иван, 26 лет). Последующий переход во вторичную социализацию происходит уже с позиции религиозного знания о социальной реальности, и целостность религиозной идентичности подвержена меньшим сдвигам, но данное состояние не исключает конфликтов на почве взаимодействия с другими индивидами, группами, теми, кто не обладает религиозным знанием и соответствующей идентичностью: «Помню, что в школе я пытался доказывать христианскую точку зрения. Потом это прошло, я не создаю повода для дискриминации» (Иван, 26 лет). Таким образом, когда в повседневную реальность человека с детских лет включены компоненты религиозной идентичности, посредством эмоционального вовлечения исключается кризис идентичности, его собственная самоидентификация на основе интернализированного религиозного знания от родителей приобретает стабильность и непрерывность.

Однако возможны случаи, когда в светской семье негативное отношение к религии выступает как барьер на пути религиозной социализации: «Приходилось врать... меня закрывали дома» (Марина, 26 лет). При условии воцерковления вне семьи предпосылкой для формирования интереса к религии выступает личная эмоциональная и когнитивная заинтересованность. Когда у человека появляются свобода действия и право самостоятельно выбирать, то знакомство со знанием о религии происходит опосредованно через агентов религиозной институциональной реальности, например, ими могут стать друзья, коллеги или просто материальные объекты, обладающие религиозной символикой (храм, крест, книги и т. д.): «В моей жизни появилась одна преподавательница литературы... говорила, что смысл жизни в вере» (Марина, 26 лет); «Поняла, что христианство мне небезразлично, года за два до того, как пришла в храм... поиск начался с любимой литературы - Достоевского» (Светлана, 24 года); «В 2000-е годы были теракты... и я задумался, мои предки были мусульманами, разве они могли быть приверженцами такой страшной религии... я отправился со своими вопросами в мусульманскую общину» (Михаил, 28 лет).

Коммуникативная практика на этом этапе имеет большое значение для формирования религиозной идентичности, поскольку за счет общения с другими для индивида актуализируются ценность религиозного знания и связь между религиозной идентичностью и другими идентичностями, например культурной и гражданско-политической. Поэтому для данного периода «пассивного» воцерковления может быть характерен поиск альтернатив религиозного знания, когда человек посещает различные религиозные группы, сравнивает религиозные течения и вероисповедания: «Православие меня тогда почему-то не влекло... Однажды я забрел на собрание пятидесятников... Однажды услышал про адвентистов седьмого дня. И я пошел знакомиться» (Михаил, 28 лет).

Процесс формирования религиозной идентичности на этапе вторичной социализации скрывает в себе две проблемные области. Первая заключается в интернализации религиозных ценностей и норм как новых социальных. Вторая состоит в адаптации интернализованного религиозного знания и модели религиозного поведения к жизни в секулярном обществе: «Во мне происходила страшная борьба, сомнения, и я спрашивал себя, зачем мне храм» (Павел, 26 лет). О проблеме ценностных противоречий писала В.Ф. Чеснокова в работе «Тесным путем: процесс воцерковления населения России в конце XX в.». По словам исследователя, у воцерковляющегося проявляется полярное противоречие двух ценностных ориентаций - от «любви к себе - к миру» до «любви к Богу», христианство уводит человека из «мирской жизни», предлагая ему способы противостояния «мирской идеологии». Богатству противопоставляется бескорыстие. Стремлению к власти - смирение. «В целом высокой ценности человеческого счастья противостоит высокая ценность терпения скорбей ради спасения души» [14].

Активному периоду религиозной социализации сопутствует закрепление религиозного знания у личности за счет формирования на его основе системы религиозных потребностей, ценностных ориентаций. Здесь агентами религиозной социализации человека выступают уже священники и приходская община. Вспоминая опыт общения со священниками, молодые люди отмечали, что встречали внимательных и рассудительных слушателей/наставников. Именно диалог со священником становится завершающим моментом в религиозной социализации. Как первичные агенты религиозного института священники осуществляют адаптационную, просветительскую, поддерживающую функции, тем самым санкционируют и закрепляют религиозное знание и поведение личности.

Стоит отметить, что религиозная социализация - это процесс, не ограниченный статичной точкой. Активная интеграция в православное сообщество и накопленные религиозные знания позволяют молодым людям транслировать свою идентичность через социальную деятельность, например с помощью организации и ведения православных молодежных клубов. Также в ходе исследования мы столкнулись с уникальным опытом - когда молодежное движение создается и 
развивается не с прихода, а наоборот, молодые люди, являющиеся участниками разных объединений, религиозных проектов, своими силами организуют приход РПЦ, поддерживают и развивают приходскую общину.

Таким образом, исследованная нами религиозная идентичность имеет внутренние (когнитивный, ценностный, эмоциональный) и внешние (поведенческий, коммуникативный, статусноролевой) компоненты. Религиозная идентичность личности в контексте православного вероучения фрормируется как с внешней стороны - от коммуникативных практик в православном сообществе (участия в православных молодежных мероприятиях, евангельских чтениях, конференциях, паломнических поездках), так и с внутренней - путем обретения индивидуального мистического христианского опыта.

Каждый из периодов формирования религиозной идентичности может быть прерван и заменен компонентами других идентичностей, не относящихся к религиозной. Например, потеря социально-ролевого статуса внутри церкви способна привести человека к разрыву социальных связей с религиозной средой. Впоследствии индивид может потерять доверие к церкви как институту и вступить на путь религиозной десоциализации (расцерковления). При условии сохранения веры в Бога идентичность станет внеинституциональной православной (по самоопределению), отказ от веры трансформирует данный процесс (десоциализации) в состояние отказа от религиозной идентичности.

В целом в современном обществе религиозная идентичность не может являться завершенной, поскольку ценностная конкуренция между светским и религиозным знанием и процесс глобализации, размывающий институциональные границы, ставят человека в условия постоянного поиска собственной индивидуальной идентичности.

\section{Ссылки и примечания:}

1. Исследование выполнено при финансовой поддержке РФФИ, проект № 16-03-00387-ОГН

2. Пронина Т.С. Типология религиозной идентичности: аналитика религиозности современного российского общества : дис. ... д-ра филос. наук. СПб., 2015. 384 с. ; Рыжова С.В. О соотношении православной идентичности и гражданского сознания // Гражданские, этнические и религиозные идентичности в современной России. М., 2006. С. 141-168.

3. Бергер П., Лукман Т. Социальное конструирование реальности: трактат по социологии сознания. М., 1995.323 с.

4. Бауман 3. Индивидуализированное общество. М., 2005. 390 с.

5. Родоначальником социологического понимания идентичности личности традиционно считают Дж.Г. Мида, который трактовал ее как способность человека воспринимать свое поведение как связное, единое целое, равновесную систему импульсивного, внутрипсихического I и социального Ме, что гарантирует успешную адаптацию.

6. Бергер П., Лукман Т. Указ. соч. С. 211-213.

7. Абельс Х. Интеракция, идентичность, презентация. Введение в интерпретативную социологию. СПб., 2000. 272 с

8. Бергер П., Лукман Т. Указ. соч. С. 231

9. Там же. С. 224

10. Там же. С. 279 .

11. Bauman Z. Migration and Identities in the Globalized World // Philosophy \& Social Criticism. 2011. Vol. 37, no. 4. P. 425435. https://doi.org/10.1177/0191453710396809.

12. Palese E. Zygmunt Bauman. Individual and Society in the Liquid Modernity // SpringerPlus. 2013. Vol. 2, no. 1. https://doi.org/10.1186/2193-1801-2-191.

13. Павлова О.Н. Идентичность: история формирования взглядов и ее структурные особенности. М., 2001.

14. Чеснокова В.Ф. Тесным путем: процесс воцерковления населения России в конце XX в. M., 2005.304 с.

\section{References:}

Abels, H 2000, Interaction, Identity, Presentation. Introduction to Interpretive Sociology, St. Petersburg, 272 p., (in Russian). Bauman, Z 2011, 'Migration and Identities in the Globalized World', Philosophy \& Social Criticism, vol. 37, no. 4, pp. 425435. https://doi.org/10.1177/0191453710396809.

Bauman, Z 2005, The Individualized Society, Moscow, 390 p., (in Russian).

Berger, P \& Luckmann, T 1995, The Social Construction of Reality. A Treatise in the Sociology of Knowledge, Moscow, pp. 211-213, 224, 231, 279, (in Russian).

Chesnokova, VF 2005, In a Close Way: Churching of the Russian People at the End of the 20th century, Moscow, 304 p., (in Russian).

Palese, E 2013, 'Zygmunt Bauman. Individual and Society in the Liquid Modernity', SpringerPlus, vol. 2, no. 1. https://doi.org/10.1186/2193-1801-2-191.

Pavlova, ON 2001, Identity: the Historical Background to Views and Its Structural Features, Moscow, (in Russian).

Pronina, TS 2015, Typology of Religious Identity: Analysis of the Religiosity of Modern Russian Society, D.Phil. thesis, St. Petersburg, 384 p., (in Russian).

Ryzhova, SV 2006, 'On the Relationship between Orthodox Identity and Civil Consciousness', Grazhdanskiye, etnicheskiye i religioznyye identichnosti v sovremennoy Rossii, Moscow, pp. 141-168, (in Russian). 